\title{
Semantic Expressions of Mental Health During Covid-19 Pandemic: the Environment Impact
}

\author{
Sekar Kinanti C.N ${ }^{1 *}$, Deli Nirmala ${ }^{2}$ \\ ${ }^{1}$ Department of Linguistics, Faculty of Humanities, Diponegoro University, Semarang - Indonesia \\ ${ }^{2}$ Department of Linguistics, Faculty of Humanities, Diponegoro University, Semarang - Indonesia
}

\begin{abstract}
Covid-19 is becoming a pandemic of such magnitude that it has caused a global danger to mental health. This study aims to describe the impact of the Covid-19 pandemic on mental health. The study uses a semantic method which is used to uncover the meaning of linguistic expressions. The semantic expressions were reviewed to identify the mental health problem as the result of Covid-19 and the supporting factors for psychological symptoms. The data collection process uses note-taking techniques related to mental health as the effect of Covid-19. The result shows that a number of phrases refer to mental symptoms with people who lose their job leading to depression or social distancing and staying at home, having an influence on people because they become more likely to have mental symptoms. Based on observations from various news and articles from Kaiser Family Foundation (KFF) that refer to mental symptoms for students, workers, and women with children as the result of the Covid-19 pandemic, the researchers draw a conclusion that three mental symptoms that often occur i.e. anxiety, depressive disorder, and suicidal thoughts. Semantically, the expressions referring to the symptoms have the same meaning.
\end{abstract}

\section{Introduction}

The The COVID-19 pandemic has significantly affected people's lives in many ways, both socially and financially and in mental health. This research is concerned with mental health in human life as a result of the Covid-19 pandemic. In a statement, World Health Organization (WHO) said several factors could trigger mental health conditions, ranging from sadness, isolation, loss of income, fear, and panic caused by this pandemic [1,12]. In other words, COVID-19 impacts mental health/illness and its relationship to an environmental stressor. It leads to the impact on the environment, such as impact for students, workers, and women with children.

Mental health is very important for well-being. World Health Organization (WHO), As the Sustainable Development Goals, illustrate, mental health plays a vital role in reaching global development goals. As for the causes of international development not achieving its goals, depression is one of them, and suicide is the second leading cause of death for people aged 15 to 29 years [1]. In 2019, WHO established the WHO Special Initiative for Mental

\footnotetext{
*Corresponding author: sekaraya26@gmail.com
} 
Health (2019-2023): Universal Health Coverage for Mental Health, aiming to provide 100 million additional people in 12 priority countries with access to high-quality, affordable mental health care.

The Kaiser Family Foundation (KFF) is a non-profit organization dedicated to national health issues and the United States' role in global health policy. KFF creates and implements its policy analysis, journalism, and communications activities, sometimes collaborating with prominent news outlets. KFF uploads an article entitled The Implications of COVID-19 for Mental Health and Substance Use [5]. In that article, some phrases show semantic expressions that refer to Covid-19 and mental health that impact the environment.

There have been several previous studies examining semantic analysis. One of them is the Semantic analysis of figurative language expressions in "feature" of The Jakarta Post by Tri Rohani, Safril Arsyad, dan Irma Diani [2]. This study focuses on figurative language with the result that the type of figurative lexicons is conceptual meaning.

Semantic analysis of expressions in terms related to Covid-19 and mental health issues that impact the environment. This study is important to be further explored as it is known that the spread of the Covid-19 pandemic has not ended and has become a serious problem for the world. The purpose of this study is to show the semantics of expression referring to Covid-19 and Mental health issues found from various news and articles on KFF.

\section{Methodology}

The semantic theory is used as a method in this study to examine the meaning of linguistic expressions. This semantic expressions review aims to identify mental health problems resulting from Covid-19 and the supporting factors for psychological symptoms. Semantic analysis connects syntactic structures at various levels, such as phrases, clauses, sentences, and paragraphs, to meaning independent of the language. It also entails the removal of traits that are unique to certain language and cultural contexts [3].

Semantics is concerned with characterization meaning and its relationship. Three basic terms have become commonly used, i.e., (1) meaning, (2) sense, (3) reference. Meaning is assumed that the response will be in the form of "this or that meaning." A sense is a relationship between two lexical items, whereas a word reference is an object the word refers to [4].

The data collection process uses note-taking techniques related to mental health as a result of Covid-19. This study's data were gathered from the news and a poll conducted by KFF (Kaiser Family Foundation). This method describes the expressions used by reading the text thoroughly to find you the semantics of the expression - note-taking expressions found from readers into notes and classifying them into meaning type.

\section{Result and Discussion}

The impact of the Covid-19 pandemic leads to depressions, social distancing, or physical distancing, and those that have an effect in the home also has an impact on people becoming more overthinking and anxious [5, 11]. Self-harm and thoughts of suicide/self-harm were higher among women, Black, Asian, and minority ethnic groups, people experiencing socioeconomic deprivation, and those with mental problems, according to data from the University College London COVID-19 Social Study, which began after the epidemic [5]. The data of this study were gathered from phrases that indicate semantic expressions that refer to Covid-19 and mental health. 


\subsection{Mental condition classification}

The Diagnostic and Statistical Management of Mental Disorders (DSM) and the International Classification for Diseases (ICD) are the most extensively used psychiatric classification systems. Mental diseases are conceptualized and classified differently in the ICD and DSM. The American Psychiatric Association (APA), America's largest professional organization of psychiatrists, publishes the DSM. The ICD was developed by the World Health Organization (WHO), a United Nations body responsible for global public health. The DSM is only concerned with psychiatric diseases, but the ICD is concerned with all health illnesses and is used by a wide range of medical specialists [6].

The DSM has been modified seven times since it was initially published in 1952. Anxiety disorders, bipolar and related disorders, depressive disorders, food and eating disorders, obsessive-compulsive and related disorders, and personality disorders are included in the DSM-5 [7]. Anxiety is a mental health condition characterized by severe worry, anxiety, or fear that interferes with daily activities. Panic attacks, obsessive-compulsive disorder, and post-traumatic stress disorder are examples of anxiety disorders. Stress that is out of proportion to the severity of the incident, unwillingness to set aside a worry, and restlessness are all symptoms. Depressive disorder: People with depression often experience symptoms similar to anxiety disorders, such as nervousness, irritability, problems sleeping and concentration, and loss of interest in activities. Major depression is characterized by a continuous feeling of melancholy or loss of interest, leading to various behavioural and physical symptoms. Changes in sleep, hunger, energy level, attention, daily behaviour, or self-esteem may be among them. Suicide ideas are sometimes linked to depression. Obsessive-compulsive, Obsessions that lead to repeat behaviours or compulsions, marked by irrational thoughts and anxieties that lead to obsessive behaviours [8].

\subsection{Students, Workers, and Women with Children}

The economic downturns indicate that job losses increase depression. Adults in households with job loss or lower income are at high risk of symptoms of mental illness [5]. Women with children are more likely to experience anxiety and depression disorder symptoms because they have to educate their children while school is closed. Various pandemic-related effects for young adults have occurred, including university closures, loss of jobs, and isolation.

Students who are supposed to study at school and meet their friends, during this pandemic, students have to look at home or study online. The difference that occurs with the decrease in the level of interaction that causes excessive anxiety can be seen.

Many adults are reporting specific adverse effects on their mental health and well-being, such as difficulty sleeping $(36 \%)$ or eating $(32 \%)$ due to worry and stress over the coronavirus, increases in alcohol consumption or substance use $(12 \%)$, and worsening chronic conditions (12\%), according to a KFF Health Tracking Poll from July 2020 [5].

Many workers who work outside the office face a greater risk of contracting the coronavirus [5]. These workers were more likely to experience symptoms of anxiety or depressive disorders, initiating or increasing drug use, and suicidal thoughts [5] during the Covid-19 pandemic. The Covid-19 pandemic triggers suicide is the solution to ending the problem as a result of the pandemic.

In this case, life experiences such as traumatic events, the Covid-19 Pandemic, appear to trigger anxiety disorders in people who are already prone to anxiety. Suicidal thoughts can have many causes [9], one of which is feeling like you can't handle a certain situation or are overly tired of something. During the Covid-19 pandemic, this can also trigger the emergence of thoughts of suicide or thoughts of larger suicides [10]. 


\subsection{Semantic Expressions}

The number of Covid-19 cases continues [9] to increase, which results in worsening mental health. The conceptual meaning can be explored for the analysis from words that have meaning and refer to Covid-19 and mental health. Semantics is concerned with characterization meaning and its relationship. Three basic terms have become commonly used, i.e., (1) meaning, (2) sense, (3) reference [4].

Meaning is assumed that the response will be in the form of "this or that meaning". The notion of sense and reference is central to the study of meaning [3]. Reference is the relationship between a phrase or word and the things it represents in the world. The exact thing that the word or phrase is referring to as a reference. There are two types of reference: (1) Variable Reference and (2) Constant Reference. A variable reference is an expression used in speech to refer to something or someone. A constant reference is any expression that has more than one reference or many potential references.

Table 1. Types of Reference.

\begin{tabular}{|c|c|c|c|}
\hline Phrases & $\begin{array}{c}\text { Variable } \\
\text { Reference }\end{array}$ & $\begin{array}{l}\text { Constant } \\
\text { Reference }\end{array}$ & $\begin{array}{c}\text { The } \\
\text { Expression } \\
\text { s }\end{array}$ \\
\hline Covid-19 & $\begin{array}{c}\text { Refer to } \\
\text { different } \\
\text { types of } \\
\text { that object }\end{array}$ & $\begin{array}{l}\text { Refer to the } \\
\text { same thing }\end{array}$ & $\begin{array}{c}\text { Virus, } \\
\text { disease, } \\
\text { pandemic, } \\
\text { flu. }\end{array}$ \\
\hline Anxiety & $\begin{array}{l}\text { Refer to } \\
\text { different } \\
\text { types of } \\
\text { that object }\end{array}$ & - & $\begin{array}{l}\text { Fears, } \\
\text { loneliness, } \\
\text { guilty. }\end{array}$ \\
\hline Bipolar & $\begin{array}{l}\text { Refer to } \\
\text { different } \\
\text { types of } \\
\text { that object }\end{array}$ & - & $\begin{array}{c}\text { Moody, } \\
\text { alter ego, } \\
\text { happy, sad, } \\
\text { crazy. }\end{array}$ \\
\hline Suicide & $\begin{array}{l}\text { Refer to } \\
\text { different } \\
\text { types of } \\
\text { that object }\end{array}$ & - & $\begin{array}{c}\text { It can refers } \\
\text { to different } \\
\text { object(perso } \\
\mathrm{n} / \text { thought/ac } \\
\text { tion) }\end{array}$ \\
\hline Depressive & $\begin{array}{c}\text { Refer to } \\
\text { different } \\
\text { types of } \\
\text { that object }\end{array}$ & - & $\begin{array}{l}\text { Sadness, } \\
\text { sick, fears, } \\
\text { hallucinate. }\end{array}$ \\
\hline
\end{tabular}

Sense is the place of expressions in the language on the system of semantic relations with other expressions. Expression is the essence of irreplaceable meaning. 
Table 2. Examples of Sense in Phrase.

\begin{tabular}{|c|c|c|}
\hline Phrase & Synonym & The Expressions \\
\hline Covid-19 & $\begin{array}{c}\text { Coronavirus } \\
2019-n C o V \\
\text { a disease caused by a } \\
\text { new strain of } \\
\text { coronavirus. 'CO' stands } \\
\text { for corona, 'VI' for a } \\
\text { virus, and 'D' for disease. }\end{array}$ \\
\hline '19' for 2019
\end{tabular}

Table 3. Sense in Sentence.

\begin{tabular}{|c|c|}
\hline Sense & Sentence \\
\hline Depression & $\begin{array}{l}\text { One of the main causes of disability is } \\
\text { depression. }\end{array}$ \\
\hline $\begin{array}{l}\text { Triggers } \\
\text { Solution } \\
\text { To ending }\end{array}$ & $\begin{array}{l}\text { The Covid-19 pandemic triggers suicide } \\
\text { is the solution to ending the problem as a } \\
\text { result of the pandemic. }\end{array}$ \\
\hline
\end{tabular}

The relationship between sense and reference is abstract; it has no real object and must be imagined and compared with existing experiences. References are concrete, can be proven by things in the real world, and can be directly proven. Not every expression has a reference, but it is different with expressions that have meaning have a sense.

From the data on the number of expressions that refer to mental health as the impact of Covid-19, it is found that three mental health conditions are often experienced by students, workers, and women with children. However, these expressions (anxiety, depression, and suicide thoughts) are experienced mainly by students and workers. Women with children may have more mental health symptoms due to the pressure of teaching their children at home during the Covid-19 pandemic.

\section{Conclusion}

Researchers draw the following conclusions based on observations from various news that refer to mental symptoms for students, workers, and women with children as a result of the Covid-19 pandemic. Many expressions show symptoms regarding mental health due to the impact of Covid-19. Three mental symptoms often occur, i.e. anxiety, depressive disorder, 
and suicidal thoughts. Students and workers are the most affected by Covid-19, which causes poor mental health [5]. As is well known, mental health is very important in social life and the environment.

\section{References}

1. J. Swendsen, Covid-19 and mental health: How one pandemic can reveal another. Journal of Behavioral and Cognitive Therapy, Elsevier Mason SAS, 30, 161-163 (2020)

2. Rohani, Tri, S. Arsyad, and I. Diani, Semantic Analysis of Figurative Language Expressions in "Feature" Of The Jakarta Post. English Education Postgraduate Program Bengkulu University Indonesia, Journal of Applied Linguistics and Literature, 3, 1 (2021) Retrieved from: https://ejournal.unib.ac.id./

3. Healsey, Brenda and Michael B. Smith James R. Hurford, Semantics: A Course Book (second edition) Cambridge University Press United Kingdom (2009)

4. G. Leech, Semantics: The Study of Meaning, Penguin Books London (1974)

5. Nirmita, Panchal, R. Kamal, C. Cox, and R. Garfield, The Implications of Covid-19 for Mental Health and Substance Use, KFF (2021) Retrieved from: https://www.kff.org/

6. C. Apter, An introduction to the classification of mental disorder: the DSM and the ICD. Mental Health Today (2019) Retrieved from: https://www.mentalhealthtoday.co.uk/

7. APA. Diagnostic and Statistical Manual of Mental Disorder, DSM-5 (fifth ed), American Psychiatric Publising (2013)

8. K. Cherry, Diagnostic and Statistical Manual (DSM) Overview, Verry Well Mind (2021) Retrieved from: https://www.verywellmind.com/

9. B. Gavin, J. Lyne, and F. McNicholas, Mental Health and the Covid-19 pandemic looking back and moving forward. Irish Journal of Psychological Medicine, Cambridge: Cambridge University Press, 37, 247-249 (2020) Retrieved from: https://www.cambridge.org/core

10. R. Meredith, Covid-19 Pandemic likely have 'profound' effect on mental health, BBC News (2021) Retrieved from: https://www.bbc.com/

11. B. Sutrisno, Drown-out pandemic causes various mental health problems: Groups, The Jakarta Post (2020) Retrieved from: https://www.thejakartapost.com/

12. WHO. Health Topics. Mental Health (2021) Retrieved from: https://www.who.int/ 